\title{
Influence of fertilization systems to the soil inorganic compounds. Case study: monocultures of cereals, leguminous and oleaginous
}

\author{
Chitimus A.D. ${ }^{1}$, Nedeff V. ${ }^{1,2}$, Muscalu (Plescan) $0 .{ }^{3}$, Mosnegutu E. ${ }^{1}$, Barsan N. ${ }^{1}$, Panainte-Lehadus M. ${ }^{1}$, Tomozei C. ${ }^{1}$ \\ ${ }^{1}$ Vasile Alecsandri University of Bacau, Faculty of Engineering, 157 Calea Marasesti, 600115 Bacau, Romania \\ ${ }^{2}$ Gheorghe lonescu Sisesti, Academy of Agricultural and Forestry Sciences Bucharest, 61 Marasti Blvd., 01146, Bucharest, Romania \\ ${ }^{3}$ Romanian Waters - National Administration of Siret Basin, 1 Cuza Voda St., 600274 Bacau, Romania \\ Received: 21/04/2021, Accepted: 15/06/2021, Available online: 15/08/2021 \\ *to whom all correspondence should be addressed: e-mail: emos@ub.ro
} https://doi.org/10.30955/gnj.003678

\section{Graphical abstract}

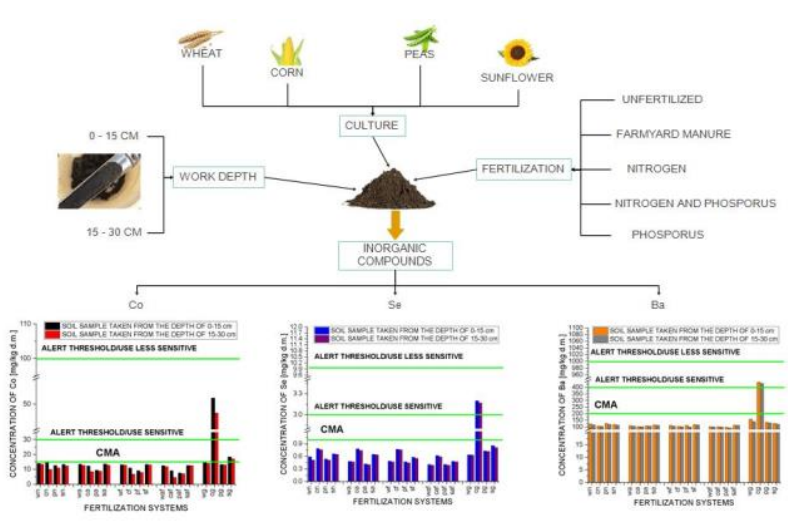

Abstract

The main objective of this article is to observe the variation of the content of inorganic compounds in the soil (cobalt, selenium, barium) under the influence of fertilization systems applied to dif-ferent monocultures of cereals (wheat, corn), leguminous (peas) and oleaginous (sunflower). High concentrations of cobalt, selenium and barium with phytotoxicity effect on the soil and future crops were recorded mainly in the experimental parcels cultivated with corn, respectively with sun-flower and fertilized with farmyard manure. The highest phytotoxicity effect on soil and future crop was recorded in the case of cobalt, for the experimental monoculture variant of corn fertilized with farmyard manure where the cobalt concentration in the soil exceeded the alert threshold/sensitive use for inorganic compounds in the soil (51.2 mg/kg d.m.).

Keywords: Inorganic compounds, fertilization systems, monoculture.

\section{Introduction}

The use of mineral and organic fertilizers increases agricultural production. The application of fertilizers such as nitrogen, phosphorus and nitrogen-phosphorus over a long period leads to a decrease in the content of soil micronutrients and macronutrients (Adamiak and Adamiak, 2015; Bindraban et al., 2015; Diacono and Montemurro, 2010; Gomaa et al., 2015; Huňady and Hochman, 2014; Scherer et al., 2011; Sobolewska et al., 2020; Vodyanitskii, 2016).

The purpose of using fertilizers is that the nutrients lead the plant grow in an optimum time. In reality, not all nutrients from fertilizers are used by plants. About $20-80 \%$ of the nutrients that come from organic and mineral fertilizers accumulate temporarily in the soil due to soil chemistry, which prevents immediate absorption into the plant (Basso, 2009; Bindraban et al., 2015; Vodyanitskii, 2016).

For the application of an efficient fertilization system, both for soil and for plant crops, it is necessary an analysis of the soil from a chemical, physical and mechanical point of view, an analysis that will provide information's related to the nutrients soil supply (Bindraban et al., 2015).

Wheat culture offers many advantages for soil and human consume such as (Adamiak and Adamiak, 2015; Bindraban et al., 2015; Diacono and Montemurro, 2010; Gomaa et al., 2015; Huňady and Hochman, 2014; Scherer et al., 2011; Sobolewska et al., 2020; Vodyanitskii, 2016): ensures satisfactory productions everywhere where it is cultivated, winter wheat reacts well to the application of fertilizers organic and mineral, farmyard manure can be applied directly to autumn wheat.

Wheat is very exigent to fertilization, due to the fact that: the root system is poorly developed and has a low capacity to use the hardly soluble nutrients in the soil (Basso et al., 2009; Maucieri et al., 2019; Muscalu et al., 2018; Woźniak, 2019).

Corn presents a number of peculiarities (Basso, 2009; Bindraban et al., 2015; Muscalu et al., 2018; Muscalu et al., 2019; Vodyanitskii, 2016; Woźniak, 2019) as a great ecological plasticity and can be cultivated in different climatic conditions. Also, it can be cultivated without special problems in monoculture for several years. Capitalizes very well on organic and mineral fertilizers, as well as irrigation water. Corn for grains leave after the 
harvest, in most cases, a soil poor in water and a large amount of vegetable waste (Bindraban et al., 2015; Vodyanitskii, 2016).

In the case of leguminous crops for grains (peas) the root system is well developed in depth, ensuring a good loose of the soil. After harvest, the peas leave a soil rich in nitrogen (Barsan et al., 2020; Basso et al., 2009; Belay et al., 2002; Bindraban et al., 2015; Heffer and Prud'homme, 2008; Jannoura et al., 2013; Muscalu et al., 2019; Shapiro and Wortmann, 2006; Sharar et al., 2003; Sangar et al., 2017; Ting-Hui et al., 2006; Vodyanitskii, 2016).

In case of the culture of oleaginous - sunflower, it can be stated that (Bindraban et al., 2015; Massignam et al., 2009; Rashid et al., 2014; Schultz et al., 2018; Vodyanitskii, 2016) the structural and fertility condition of the soil after harvesting the sunflower crop is good. Also, has moderate requirements for nitrogen and phosphorus fertilization, but has higher requirements for potassium. Compared to corn, sunflower makes better use of soils with medium fertility and better withstands at water hydric stress.

In the field of soil chemistry, there are a number of heavy metals with a toxic effect on the soil, as well as on plant crops. Excess of barium and selenium from soil, water and plants, can disrupt the calcium content in the human body, leading to serious diseases (Bindraban et al., 2015; Vodyanitskii, 2016). Some Romanian regulations indicates the maximum permissible concentrations of barium in the soil is $200 \mathrm{mg} / \mathrm{kg} \mathrm{d.m.,} \mathrm{for} \mathrm{selenium} \mathrm{is} 1 \mathrm{mg} / \mathrm{kg} \mathrm{d.m}$. and for cobalt $15 \mathrm{mg} / \mathrm{kg} \mathrm{d.m.} \mathrm{(Order} \mathrm{no.} \mathrm{756,} \mathrm{2011).}$

The present research aimed to determine the variation of the content of inorganic compounds in the soil (cobalt, selenium, barium) depending on the fertilization system applied to different monocultures of cereals, leguminous and oleaginous (wheat, corn, peas, sunflower).

\section{Experimental part}

The soil samples were collected (Zeenit, 2009) from an experimental field, part from a research institute (National Agricultural Research and Development Institute Fundulea, Romania, experiments have been carried out following a two-factor experience, stationary and multiannual, mounted in 1968 and up to date, with reference to emphasizing the effect of fertilization sequence on soil), after harvesting the existing cereals, leguminous and oleaginous on the experimental field. The content of barium, selenium and cobalt from soil, was determinate in the laboratory, by using the atomic absorption spectrometer, ZEENIT AAS (method atomic absorption spectrometer) (ISO 11464:2006 (2006). The forms of the experiments performed on the experimental field are presented in Figure 1.

The original conditions of the soil before the cultivations are presented in Table 1.

The measurement values of the analyzed parameters were compared with maximum permissible concentrations (CMA) for soil inorganic compounds, according with Romanian Order no. 756 (Order no. 756, 2011).
Table 1. Original conditions of the soil before the cultivations

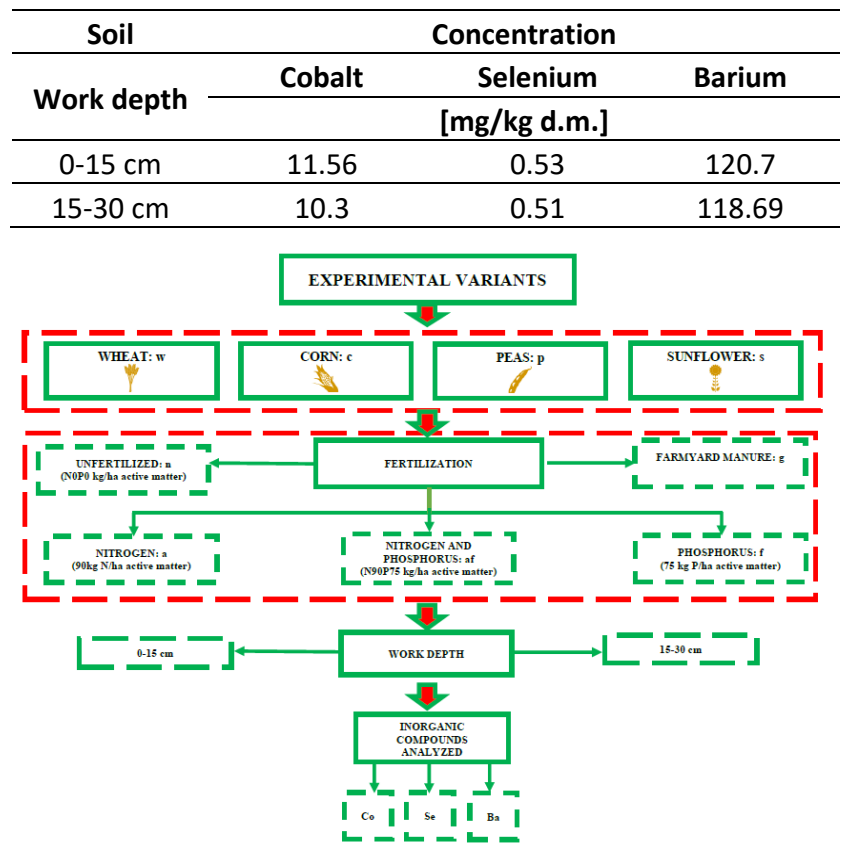

Figure 1. Working methodology

\begin{tabular}{ll}
\multicolumn{2}{l}{ Abbreviations } \\
wn & wheat monoculture unfertilized \\
cn & corn monoculture unfertilized \\
pn & peas monoculture unfertilized \\
sn & sunflower monoculture unfertilized
\end{tabular}

wa wheat monoculture fertilized with nitrogen $(90 \mathrm{~kg} \mathrm{~N} / \mathrm{ha}$ active matter)

ca corn monoculture fertilized with nitrogen $(90 \mathrm{~kg} \mathrm{~N} / \mathrm{ha}$ active matter)

pa peas monoculture fertilized with nitrogen $(90 \mathrm{~kg} \mathrm{~N} / \mathrm{ha}$ active matter)

sa sunflower monoculture fertilized with nitrogen $(90 \mathrm{~kg}$ $\mathrm{N} /$ ha active matter)

wf wheat monoculture fertilized with phosphorus $(75 \mathrm{~kg}$ $\mathrm{P} /$ ha active matter)

cf corn monoculture fertilized with phosphorus $(75 \mathrm{~kg}$ $\mathrm{P} /$ ha active matter)

pf peas monoculture fertilized with phosphorus $(75 \mathrm{~kg}$ $\mathrm{P} /$ ha active matter)

sf sunflower monoculture fertilized with phosphorus (75 $\mathrm{kg} \mathrm{P} /$ ha active matter)

waf wheat monoculture fertilized with nitrogen and phosphorus (N90P75 kg/ha active matter)

caf corn monoculture fertilized with nitrogen and phosphorus (N90P75 kg/ha active matter)

paf peas monoculture fertilized with nitrogen and phosphorus (N90P75 kg/ha active matter)

saf sunflower monoculture fertilized with nitrogen and phosphorus (N90P75 kg/ha active matter)

wg wheat monoculture fertilized with farmyard manure

cg corn monoculture fertilized with farmyard manure 
pg peas monoculture fertilized with farmyard manure

sg sunflower monoculture fertilized with phosphorus farmyard manure.

\section{Results and discussion}

For the inorganic cobalt compound, respectively for the experimental variant $w g-0-15 \mathrm{~cm}$ (wheat monoculture fertilized with farmyard manure, working depth 0-15 cm, Figure 2) the highest concentration was registered, this being $3.26 \%$ lower than the maxi-mum permissible concentration for inorganic compounds in soil $(15 \mathrm{mg} / \mathrm{kg}$ d.m.).

The lowest value of cobalt concentration was resulted from in the case waf $-15-30 \mathrm{~cm}$, the resulting value being $78.6 \%$ of the CMA for inorganic compounds in the soil. For none of the five fertilization systems applied to wheat-grown soil, there were no exceedances of the CMA for inorganic compounds in the soil, respectively for cobalt.

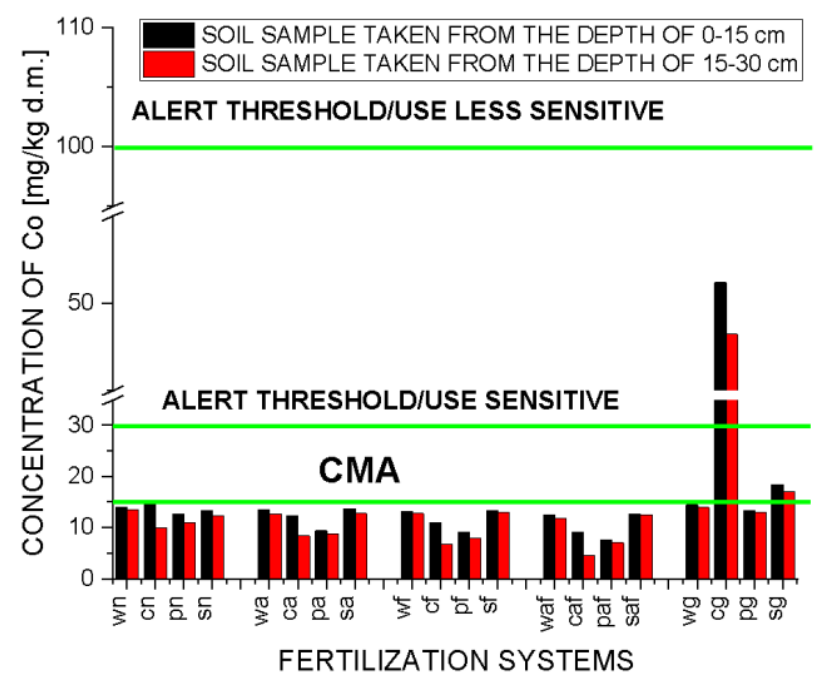

Figure 2. The concentration of inorganic compounds in the soil cobalt, after harvesting the monocultures of wheat, corn, peas and sunflower, to which different fertilization systems were applied

In the case of the $\mathrm{cn}-0-15 \mathrm{~cm}$ experiment, the concentration of cobalt from the soil exceeded the CMA for inorganic compounds in the soil with $103 \%$ (Figure 2).

For the fertilization system with farmyard manure in the case of experiments of the form $\mathrm{cg}-0-15 \mathrm{~cm}$ and $\mathrm{cg}-15-30$ $\mathrm{cm}$, the concentration of cobalt from the soil has exceeded the alert threshold/use sensitive (AT/SU) for inorganic compounds in the soil with $170.66 \%$, respectively with $160.76 \%$.

For all other experimental variants on which corn was grown, the CMA was not exceeded for inorganic compounds in the soil, for cobalt respectively. For none of the five fertilization systems applied to the soil cultivated with peas (Figure 2), there were no exceedances of the CMA for inorganic compounds in the soil, respectively for cobalt (the maximum concentration of inorganic compound cobalt was recorded for the experiment of the form pg - 0-15 cm, this having the value of $13.37 \mathrm{mg} / \mathrm{kg}$ d.m.).
In the case of oleaginous sunflower crops, increases in cobalt concentration were observed (Figure 2) over the CMA for inorganic compounds in the soil, for experiments of the form sg - 0-15 cm (with $123.33 \%$ higher) and sg - 15$30 \mathrm{~cm}$ (with 114\% higher). The recorded concentrations were above CMA for inorganic compounds in the soil, but below the AT/SU (alert threshold/sensitive use) value for experiments of the form sg $-0-15 \mathrm{~cm}$ and $\mathrm{sg}-15-30 \mathrm{~cm}$. Figure 3 shows the values of the inorganic compound content of sol-selenium, respectively for the monocultures of wheat, corn, peas and sunflower, to which different fertilization systems were applied.

The concentration of the inorganic selenium compound in the soil varied as follows (Figure 3):

- Wheat monoculture: all values recorded for selenium in the soil were below the CMA for inorganic compounds in the soil $(1 \mathrm{mg} / \mathrm{kg} \mathrm{d} . \mathrm{m}$.), the maximum concentration of selenium being recorded for the experiment form wg - 0-15 cm (being $36 \%$ lower).

- Corn monoculture: increases in selenium concentration were observed for experiments of the form $\mathrm{cg}-0-15 \mathrm{~cm}$ and $\mathrm{cg}-15-30 \mathrm{~cm}$ over AT/SU (3 $\mathrm{mg} / \mathrm{kg}$ d.m.) for inorganic compounds in the soil by $106.66 \%$, respectively with $105.66 \%$.

- Pea monoculture: all values recorded for selenium in the soil were below the CMA for inorganic compounds in the soil, the maximum concentration of selenium being recorded for the experiment of the form $\mathrm{mg}-0-15 \mathrm{~cm}$ (being $27 \%$ lower).

- Sunflower monoculture: all values recorded for selenium in the soil were below the CMA for inorganic compounds in the soil, the maximum concentration of selenium being recorded for the experiment of the form $\mathrm{sg}-0-15 \mathrm{~cm}$ (being $14 \%$ lower).

For the barium inorganic compound, respectively for the experimental variant of the form wg (wheat monoculture fertilized with farmyard manure, working depth 0-15 cm, Figure 4), the highest concentration was registered, this being $20.5 \%$ lower than CMA for soil inorganic compounds (200 mg/kg d.m.).

The lowest value of barium concentration resulted from the form experiment waf- $15-30 \mathrm{~cm}$, the resulting value being $50.52 \%$ of the CMA for inorganic compounds in the soil. For none of the five fertilization systems applied on wheat-grown soil, there were no exceedances of the CMA for inorganic compounds in the soil, respectively for barium. For the experimental variants of the form: $\mathrm{cn}, \mathrm{ca}$, cf and caf on which corn was grown, the CMA was not exceeded for inorganic compounds in the soil, respectively for barium. For the fertilization system with farmyard manure, in the case of experiments of the form cg - 0-15 $\mathrm{cm}$ and $\mathrm{cg}-15-30 \mathrm{~cm}$ the concentration of barium in the soil exceeded AT/SU for inorganic compounds in the soil by $109.75 \%$ and $107.81 \%$ respectively (Figure 4 ). 


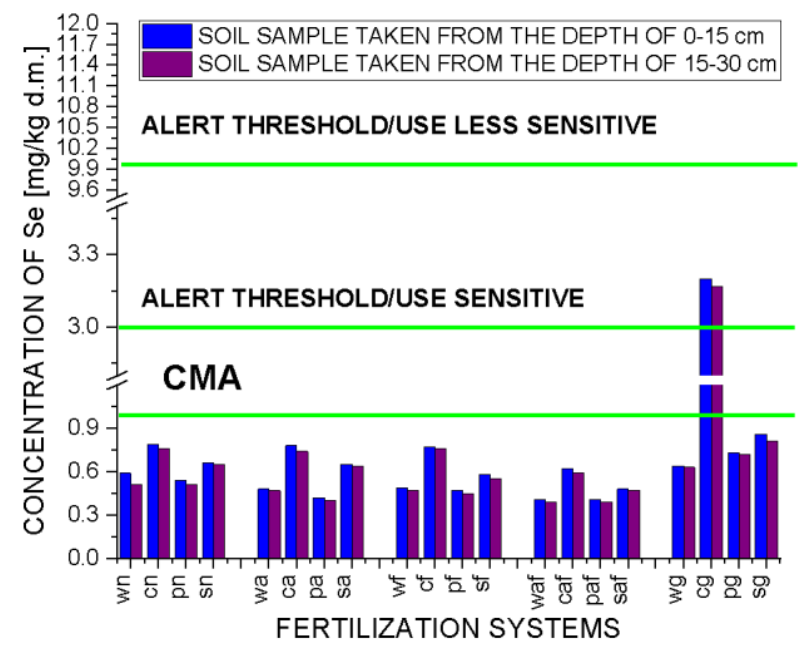

Figure 3. The concentration of inorganic compounds in the soil selenium, after harvesting the monocultures of wheat, corn, peas and sunflower, to which different fertilization systems were applied

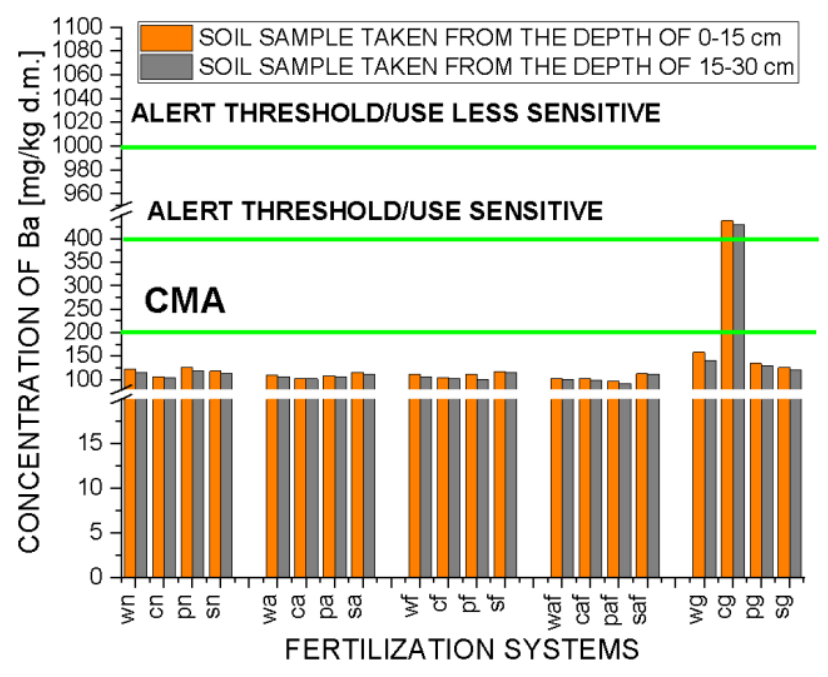

Figure 4. The concentration of inorganic compounds in the soil barium, after harvesting the monocultures of wheat, corn, peas and sunflower, to which different fertilization systems were applied

For none of the five fertilization systems applied to the soil cultivated with peas (Figure 4), there were no exceedances of the CMA for inorganic compounds in the soil, respectively for barium (the maximum concentration of inorganic compound - barium was recorded for the experiment of the form $\mathrm{pg}-0-15 \mathrm{~cm}$, this having the value of $135.06 \mathrm{mg} / \mathrm{kg} \mathrm{d.m.)}$.

For none of the five fertilization systems applied to the soil cultivated with sunflower (Figure 4), there were no exceedances of the CMA for inorganic compounds in the soil, respectively for barium (maximum concentrations of inorganic compound - barium were recorded for the experiment of the form pg - 0-15 cm and pg $-15-30 \mathrm{~cm}$, these having values between $120.73 \mathrm{mg} / \mathrm{kg} \mathrm{d.m}$. and $126.56 \mathrm{mg} / \mathrm{kg}$ d.m.).

\section{Conclusions}

According to the Romanian regulation no. 756, the cobalt content in the soil was within the normal cobalt limits for soil loading with potential pollutants for most experimental parcels. Exceptions are the experimental parcels cg and sg, where:

- The values of the cobalt content were between the limit of the normal content $(15 \mathrm{mg} / \mathrm{kg} \mathrm{d.m}$.) and the alert threshold (warning, $30 \mathrm{mg} / \mathrm{kg} \mathrm{d.m}$.) for sensitive uses for the experimental parcel sg.

- The cobalt content values ranged between the alert threshold limit (warning, $30 \mathrm{mg} / \mathrm{kg} \mathrm{d.m}$.) for sensitive uses and the alert threshold limit (warning, $100 \mathrm{mg} / \mathrm{kg}$ d.m.) for less sensitive uses for the experimental parcel sg.

Selenium concentration values showed that high amounts of residues did not accumulate in the soil, which may have phytotoxicity effects for future plant crops, with the exception of the cg experimental parcel, where the selenium content was within the alert threshold (warning, $3 \mathrm{mg} / \mathrm{kg} \mathrm{d.m.)} \mathrm{for} \mathrm{sensitive} \mathrm{uses} \mathrm{and} \mathrm{the} \mathrm{alert} \mathrm{threshold}$ limit (warn-ing, $10 \mathrm{mg} / \mathrm{kg}$ d.m.) for less sensitive uses.

The values of barium concentration for most of the analyzed experimental variants decreased, compared to the values recorded in the case of unfertilized soil parcels. This decrease in micronutrient content may indicate an absorption in the cultivated plant on the experimental plot, micronutrients being necessary for plant health.

The recording of high concentrations of cobalt, selenium and barium in the soil may be due to climatic conditions, the inability of different plant species to assimilate nutrients from the soil due to the root system, soil compaction, soil works etc.

\section{References}

Adamiak E. and Adamiak J. (2015). Changes of the chosen chemical properties of soil as a result of long-term cereal cultivation in crop rotation and monoculture. Acta Scientarum Polonorum Agricultura, 14(1), 3-10.

Barsan N., Chitimus A.D., Muscalu (Plescan) O.M., Nedeff F.M., Sandu I., Partal E., Sandu A.V. and Panainte Lehadus M. (2020). Influence of fertilizers on soils used for oleaginous crop. Revista de Chimie, 71(1), 233-238.

Basso B., Cammarano D., Grace P.R., Cafiero G., Sartori L., Pisante M., Landi G., De Franchi S. and Basso F. (2009). Criteria for selecting optimal nitrogen fertilizerrates for precision agriculture. Italian Journal of Agronomy, 4, 159-174.

Belay A., Claassens A.S. and Wehner F.C. (2002). Effect of direct nitrogen and potassium and residual phosphorus fertilizers on soil chemical properties, microbial components and maize yield under long-term crop rotation. Biology and Fertility of Soils, 35(6), 420-427.

Bindraban P.S., Dimkpa C., Nagarajan L., Roy A. and Rabbinge R. (2015). Revisiting fertilisers and fertilisation strategies for improved nutrient uptake by plants. Biology and Fertility of Soils, 51, 897-911. 
Diacono M. and Montemurro F. (2010), Long-term effects of organic amendments on soil fertility. A review. Agronomy for Sustainable Development, 30, 401-422.

Gomaa M.A., Radwan F.I., Kandil E.E. and El-Zweek S.M.A. (2015). Efect of some macro and micronutrients application methods on productivity and quality of wheat (Triticum aestivum, L.). Middle East Journal of Agriculture Research, 4, 01-11.

Heffer P. and Prud'homme M. (2008). Outlook for world fertilizer demand, supply, and supply/demand balance. Turkish Journal of Agriculture and Forestry, 32, 159-164.

Huňady I. and Hochman M. (2014). Potential of legume-cereal intercropping for increasing yields and yield stability for selfsufficiency with animal fodder in organic farming. Czech Journal of Genetics and Plant Breeding, 50(2), 185-194.

ISO 11464:2006 (2006). Soil quality - Pretreatment of samples for physico-chemical analysis.

Jannoura R., Bruns C. and Joergensen R.G. (2013). Organic fertilizer effects on pea yield, nutrient uptake, microbial root colonization and soil microbial biomass indices in organic farming systems. European Journal of Agronomy, 49, 32-41.

Massignam A.M., Chapman S.C., Hammer G.L. and Fukai S. (2009). Physiological determinants of maize and sunflower grain yield as affected by nitrogen supply. Field Crops Research, 113 (3), 256-267.

Maucieri C., Barco A. and Borin M. (2019). Compost as a substitute for mineral $\mathrm{N}$ fertilization? Effects on crops, soil and $\mathrm{N}$ leaching. Agronomy, 9(4), 193.

Muscalu (Pleșcan) O.M., Nedeff V., Chițimuș A.D., Partal E., Bârsan N., Rusu I.D. and Sandu I.G. (2019). Influence of soil fertilization systems and crop rotation on chemical properties of the soil. Revista de Chimie, 70 (2), 536-542.

Muscalu (Plescan) O.M., Nedeff V., Chitimus A.D., Sandu I.G., Partal E., Mosnegutu E., Sandu I. and Rusu D.I. (2018). Influence of fertilization systems on physical and chemical properties of the soil. Revista de Chimie, 69(11), 3106-3111.

Muscalu (Plescan) O.M., Nedeff V., Sandu I., Chitimus A.D., Partal E., Mosnegutu E., Sandu I.G. and Tomozei C. (2019). Influence of soil fertilization systems on chemical properties of the soil. Revista de Chimie, 70(12), 4557-4565.

Order no. 756 of November 3, 1997, updated -28.06.2011 (2011). for approving the Regulation regarding the assessment of environmental pollution.

Rashid A., Ejaz A.W., Ashraf M.Y., Shamim A. and Tariq A. (2014). Does nitrogen fertilization enhance drought tolerance in sunflower, A review. Journal of Plant Nutrition, 37(11), 942963.

Schultz E., Desutter T., Sharma L., Endres G., Ashley R., Bu H., Markell S., Kraklau A. and Franzen D. (2018). Response of sunflower to nitrogen and phosphorus in North Dakota. Agronomy Journal, 110(2), 685-695.

Shapiro C.A. and Wortmann C.S. (2006). Corn response to nitrogen rate, row spacing and plant density in eastern Nebraska. Agronomy Journal, 98, 529-535.

Sharar M., Ayub S.M., Nadeem M. and Ahmad N. (2003). Effect of different rates of nitrogen and phosphorus on growth and grain yield of maize (Zea mays L.). Asian Journal of Plant Sciences, 2, 347-349.

Sobolewska M., Wenda-Piesik A., Jaroszewska A. and Stankowski S. (2020). Efect of habitat and foliar fertilization with $\mathrm{K}, \mathrm{Zn}$ and $\mathrm{Mn}$ on winter wheat grain and baking qualities. Agronomy, 10, 276.
Sangar K., Rifat H., Shakir F., Qaiser H. and Noshen A.A. (2017). Interactive use of biochar and chemical fertilizer on soil nutrients (NPK), soil water retention and biological nitrogen fixation by mash bean. Advances in Crop Science and Technology, 6(1), 328-332.

Scherer H.W., Metker D.J. and Welp G. (2011). Effect of long-term organic amendments on chemical and microbial properties of a luvisol, Soil and Environment, 57(11), 513-518.

Ting-Hui D., Xin C., Sheng-Lil G., Ming-De H. and Heng L.K. (2006). Effect of nitrogen management on yield and water use efficiency of rainfed wheat and maize in northwest China. Pedosphere, 16, 495-504.

Vodyanitskii Y.N. (2016). Standards for the contents of heavy metals in soils of some states, Annals of Agrarian Science, 14(3), 257-263.

Woźniak A. (2019). Effect of crop rotation and cereal monoculture on the yield and quality of winter wheat grain and on crop infestation with weeds and soil properties, International Journal of Plant Production, 13, 177-182.

Zeenit (2009). Atomic absorption spectrometry (AAS) Zeenit 700, Operating Manual. 